\title{
IoT based Fragrance Tester
}

\author{
Joshua Kumaresan S, Nethaji Subash Chandra R, Manikandan T, Priyanka R, Muruganandham A
}

\begin{abstract}
Perfumes and deodorant has become a major part in our daily life. Thus new technology has to be made in the field of perfume production. An exposure towards the fragrance of the perfume is required. For this case, the present day uses a tester of that particular fragrance. In this method, the misuse of the sample takes place in most of the places. A novel method is suggested such that the use of sample perfume can be utilized in an effective way.

A new device is designed and developed. This device provides a fragrance bud to the customers such that the exact fragrance in a limited amount is obtained. The consumer can control the device remotely using a mobile app. This enables a better user experience towards the perfume exposure. This technique is enabled for the high class body spray such that the producer is also benefitted with respect to income.
\end{abstract}

\section{Keywords: Perfume tester, Mobile App, Internet of Things}

\section{INTRODUCTION}

The Internet of Things (IoT) smart systems facilitate fast manufacturing of new products, on the fly optimization of industrial production and immediate response to product demands. It also modernize supply chain networks, by networking sensors, machinery and control systems together [1]. Different manufacturing equipment with networking, sensing, processing, actuation, identification and communication capabilities can be integrated using IoT. It also creates market opportunities and entirely new business for manufacturing with such smart integrated devices.

Now a day, trail perfume is used to check the fragrance of the perfume and also require a man power to monitor those things. There is wastage of perfume during the testing. Sometimes the user may long press the knob so that it causes an excess fragrance that will affect our olfactory lobes. All the markets use a common tester to get the fragrance of a particular perfume. In this method, a sample product is used and it is sprayed in a leaf so as to get the fragrance. Each and every spray costs in the case of premium sprays.

The user experience can be improved and the wastage can be reduced to a greater extent by controlling the amount of liquid produced in an effective way. A new device is developed that controls the liquid coming out from perfume

Revised Manuscript Received on November 14, 2019.

* Correspondence Author

Joshua Kumaresan S*, Asssociate Professor, Department of ECE, R.M.K. Engineering College, Kavaraipettai, India. Email: skn.ece@ rmkec.ac.in

Nethaji Subash Chandra R, Dot net developer, HnS Infotech, Chennai, India. Email: nethajirambabu@gmail.com

Manikandan T, Professor, Department of ECE, Rajalakshmi Engineering College, Chennai, India. Email: manikandan.t@ rajalakshmi.edu.in

Priyanka R, Assistant Professor, Department of ECE, Saveetha school of Engineering, Chennai, India. Email: shobanapriyams.sse@saveeths.com

Muruganandham A, Professor, Department of ECE, Rajarajeswari College of Engineering, Bengaluru, India. Email:a.muruganandham@gmail.com bottle. This product thus avoid the wastage of perfume during testing and also provide efficient marketing of the product.

\section{LITERATUER REVIEW}

Feinberg, Sheffler, Meoli and Rummel [2] found that for social behaviour of people mall is an outlet. They came to this conclusion by considering the fact that malls provide social stimulation. Lotz, Eastlick and Shim [3] compare and contrast the people coming for shopping with those coming just for entertainment. This study proves that the motivations are different for the people coming for shopping and those coming.

Sonal Kureshi, Vandana Sood, Abraham Koshy [4] analyzed the Indian market customers of Brand Store. They have detailed the nature of the consumers of exclusive brand store, depending on their psychographic and demographic characteristics. They also listed the differences between the "Browser" and "Purposive" customers. In their paper, they further studied how these differences affect the retailer..

Gangadharaiah D.N, H.N. Ramesh and Y.N.Nagaraju [5] published a paper titled "Retailing behavior of urban and rural consumers towards unorganized and organized Retail outlets". Urban and rural buying behaviour differs towards traditional outlet. Female and Male customers and also unmarried and married customers differ in their retailing behaviour. 26.8 percent urban customer prefer varieties and 39.3 of rural prefer quality products. Most urban people buy their groceries weekly once and Most of the rural people monthly once [6]. Rural people mostly use cash for buying things and urban people pay using debit cards.

Poonam Kamboj [7] published paper titled "Retail Industry: Its Growth, Opportunities and Challenges" in International Journal of Research in Finance and Marketing Vol 2, No. 2. He concluded that in USA, considering the numbers of establishments and employees retail industry is the $2^{\text {nd }}$ biggest industry. There is no denying the fact that many of the developed economies are very much relying on their retail sector as a locomotive of growth [8]. Similarly in India also, Retail Industry accounts for over eight per cent of the employment and for around ten per cent of GDP of the country making it as the largest amongst all the industries.

Zanual Bashar Bhutoo, Rambalak yadav and vikram singh [9] in their paper titled "Consumer Perception of retail outlet a comparative study of more mega store and big bazaar", analyzed the dimensions factor like personalization, facilities, Responsiveness, Flexibility, Courtesy, Privileges to regular customer, empathy and Parking space. Retail Outlets in the study, increase the sale of retail outlet and create good brand image in the mind set of consumers. The study shows that almost same type of 
consumer perception practices adopted by mega store and more big bazaar. But there is significant difference in the consumer perception practices adopted by retail outlets regarding empathy. [10]

\section{PRODUCT DESCRIPTION}

Initially the product is loaded with perfume containers of different odours and different brands. A stepper motor is placed and move dynamically near the knobs of the perfume bottle. The fragrance of the perfume is given to a cotton bud by the device. QR code sticker will be available on the surface of the device. The customer need to scan this QR code to download the "Perfume selector App" into his smart phone. The available brands and odour loaded in the product will be displayed in his phone. Then he can select any particular perfume of his choice. When the particular perfume is selected, the stepper motor presses against the specific knob and the pressure is limited such that only a small spray is provided to the cotton bud. The user can get access to the bud. The bud is taken by the user for his application. The fragrance gets blocked in cotton for a longer time thus making the easy comparison for the perfumes among the users. Thus the user exposure towards the premium perfumes can be enhanced.

At the back end, each of the perfume is given a particular ID with the rack position such that the knob is clicked in the amount of pressure given from the program. The data is processed using an Arduino Uno Micro Controller [11].

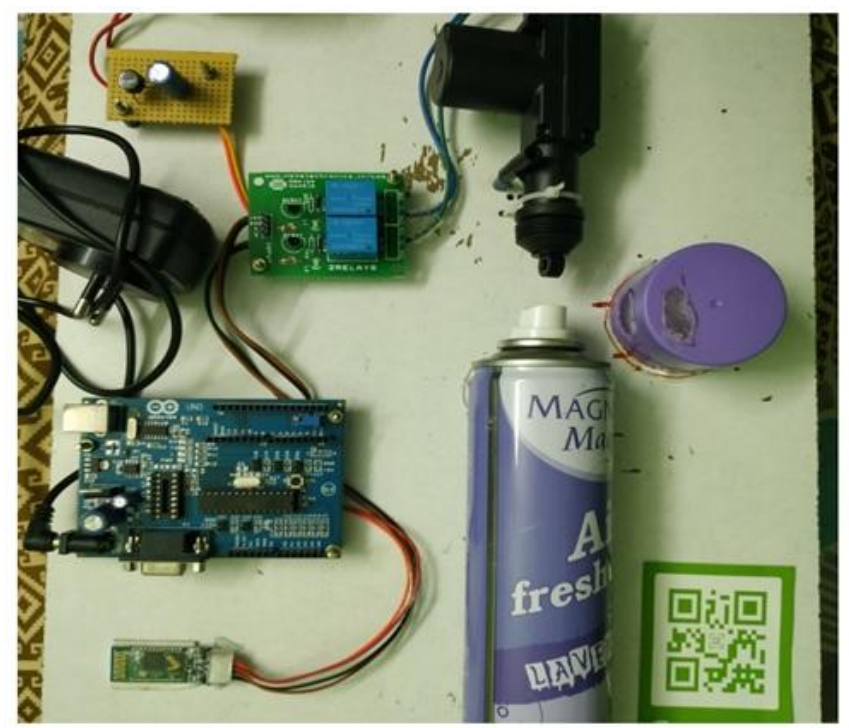

Fig.2 Product overview

\section{GENERATING QR CODE IMAGE}

In this module are creating $\mathrm{QR}$ codes for encoding the information about the products. The product contains name, code, quantity and price. Each pattern represents each module in QR code and is encoded with black and white special symbols. QR code can have more data than many other bar codes. The format of QR Code comprises of unique Finder Pattern (Position Detection Patterns) that are located at three corners of the symbol. and The position of the size, symbol and inclination can be located using this unique Finder Pattern.

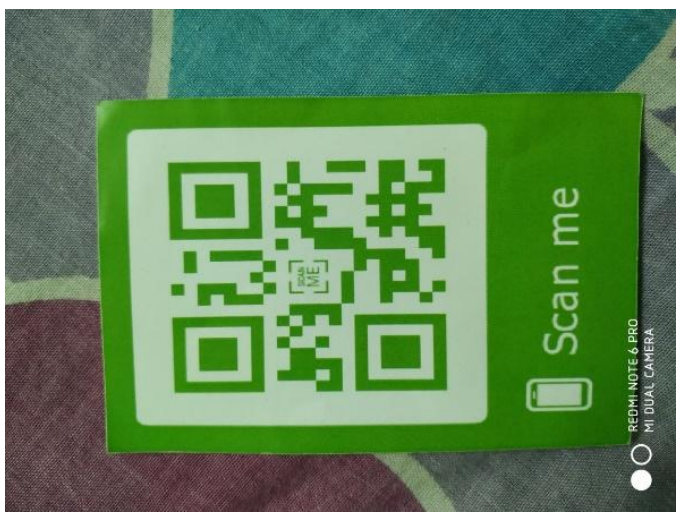

Fig.1. Generated QR code

\section{HARDWARE DESCRIPTION}

The hardware required for the product is as follows

- Mobile authentication module

- Arduino board UNO board

- Actuator controller board

- Stepper motor controller board

- Power supply unit

\section{A. Mobile authentication module}

This module is used by the customer to login their details and for authentication for the shopping processes. Then the logged user need to browse the scanner module.

Whether a specified user is authorized to access the app is determined by this authentication The validation process is done on the webserver.

\section{B. Arduino uno}

An Arduino is a microcontroller based kit that can be developed at home because of its open source hardware feature or can be purchased directly from the retailer. [12].

The Arduino Uno is an ATmega328 based microcontroller board. It has a reset button, six analog inputs, a sixteen Mega Hertz crystal oscillator, fourteen digital input/output pins (of which six are also used as PWM outputs), a USB connection, an ICSP header and a power jack.

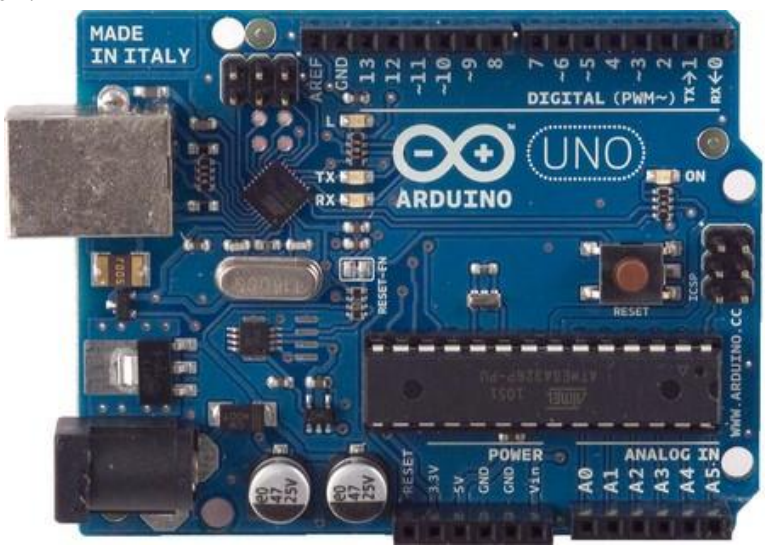

Fig 3 Arduino Uno board 


\section{Actuator Controller board}

Relays are used for effective working of most of the industrial application devices. .Relays are mechanically or electrically operated simple switches. Relays comprise of a set of contact and an electromagnet. Electromagnet carries out the switching mechanism in relays.

In our product the relays are used to switch on or off the actuator. The signal for this board will be given from Arduino Uno board. Based on the program [13], the actuator moves appropriate steps and apply pressure to the knob of perfume container. The perfume is sprayed on the cotton bud.

Fig.4 Actuator Controller board

\section{Stepper Motor Controller Board}

Since stepper motors are designed in a unique manner, they can be accurately even without any feedback. The electromagnetic coils in stepper motor are applied with both positive and negative voltage in a predetermined order. These coils controls the magnets which in turn accurately moves the shaft back and forth in small steps.

The driver circuit board controls the stepper motor. In this design, stepper motor is used to move the conveyor belt. The belt transports the bud from inside the device to the outlet where the customer collects it.

\section{Blue tooth module}

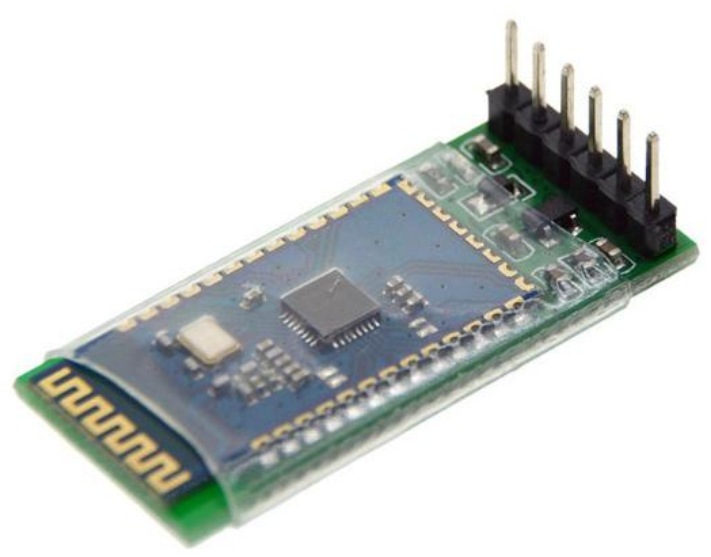

\section{Power supply unit}

Power supply is a reference to a source of electrical power. A power supply unit or PSU is the one that provides electrical energy to an output device or a more devices.

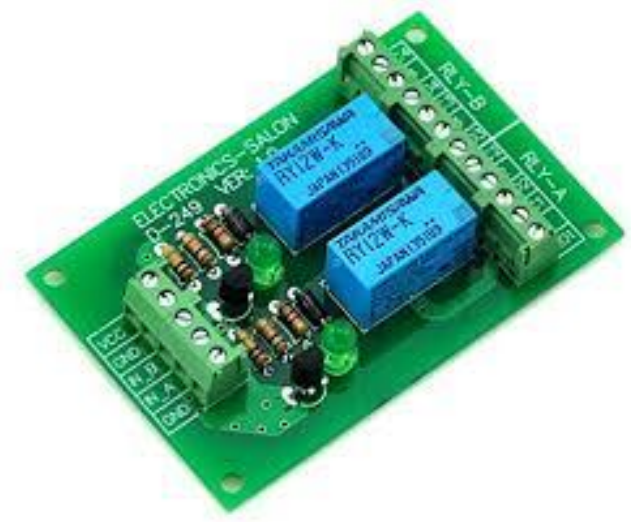

Electrical energy supplies are only most commonly called as power supply and mechanical energy and other energy supplies are rarely called as power supplies. In our product, the power supply unit supplies $5 \mathrm{~V}$ to Arduino Uno board.

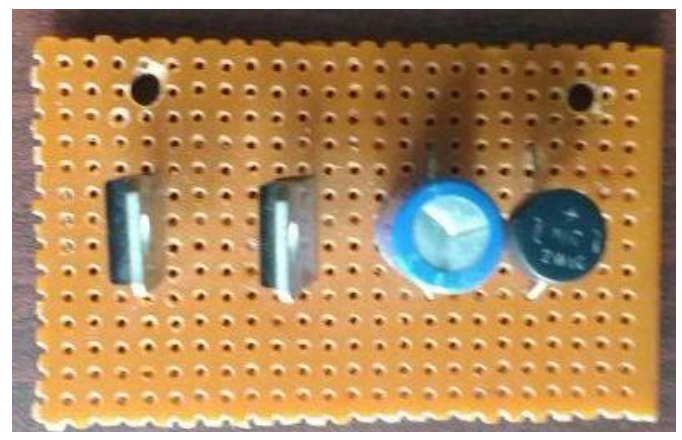

Fig.5 Power supply unit

\section{SOFTWARE DESCRIPTION}

The program is written in java and implemented into Arduino board [14]. The algorithm of the process is given below

1. Check the ID of the brand that is selected by the user.

2. Move the corresponding container in front of the actuator

3. Press the actuator against the knob so that the perfume is sprayed on the cotton bud.

4. Activate the stepper motor to move the conveyor belt so that the cotton bud is available to user.

5. Repeat steps 1 to 4 .

\section{CONCLUSION}

The user experience of the customers in buying the perfumes can be increased by this method. A perfect comparison with the exact fragrance which is unaltered with the external environment is provided to the customers. The wastage of premium perfumes can be reduced greatly thereby enhancing the seller's profit.

This is an effective method for testing the fragrance of the premium perfume. This helps the customers to get access towards all sorts of perfume with high efficiency. The wastage of the perfume in the application of the tester can be neglected in this case where in a limited amount of liquid is sprayed. Since the smell gets blocked in the cotton for a longer duration, the comparison of the fragrances can be made easier. The buds can also be used for the advertisement of the perfume, exhibiting to all the customers by placing those devices in malls, shopping complex etc.

\section{REFERENCES}

1. Karen Rose, Scott Eldridge, Lyman Chapin, "The Internet of Things: An Overview", The Internet Society, 2015

2. Feinberg, Sheffler, Meoli and Rummel, "There's Something Social Happening at the Mall, Journal of Business and Psychology", Vol. 4, No. 1 ,Sep., 1989, pp. 49-63 


\section{IoT based Fragrance Tester}

3. Lotz, Sherry L., Mary Ann Eastlick, and Soycon Shim, "Modeling Patrons' Activities at Entertainment Malls: A Study in "Flow"," AMA Educators' Proceedings: Enhancing Knowledge Development in Marketing, vol.11, 2000, pp256-257.

4. Sonal, Kureshi \& Vandana, Sood \& Abraham, Koshy, "Comprehensive Analysis of Exclusive Brand Store Customer in Indian Market”, Indian Institute of Management Ahmedabad, Research and Publication Department, IIMA Working Papers,2007.

5. Gangadharaiah D.N, H.N. Ramesh and Y.N.Nagaraju, "Retailing behavior of rural and urban consumers towards organized and unorganized Retail outlets" International Journal of Physical and Social Sciences, 2012, Vol. 2, No.6 pp: 496- 506

6. Wells, William d.; Tigert, Douglas J. "Activities, interests and opinions", Journal of Advertising Research, Aug 1971, Vol. 11 Issue 4, p27-35

7. Kamboj, Poonam and Surender Kumar Gupta. "Indian retail industry: its growth, opportunities and challenges.” International Journal of Research in IT \& Management Vol.2, No.10, October 2012.

8. Woodruffe-Burton H., S. Eccles and R. Elliott, "Towards a theory of shopping: A holistic framework," Journal of Consumer Behaviour, 2002, pp256-266.

9. Zanual Bashar Bhutoo, Rambalak yadav and vikram singh "Consumer Perception of Retail Outlets: A Comparative Study of Big Bazaar and more mega stores" IJNPME Journal, Issue 1, 2012.

10. Belk, R. "Qualitative analysis of data from the consumer behavior odyssey: The role of the computer and the role of the researchers", In L. Alwitt, (Ed) Proceedings of the Division of Consumer Psychology, 7-12,1988.

11. Jeremy Blum, Exploring Arduino: Tools and Techniques for Engineering Wizardry, John Wiley\& sons, 2013.

12. J. M. Hughes Arduino: A Technical Reference, O’Reilly,2016

13. Java Virtual Machine Tool Interface Spec:

14. http://java.sun.com/javase/6/docs/platform/jvmti/jvmti.html

15. Java Software, Sun Microsystems, Inc. Java Development Kit (JDK). http://java.sun.com/products/jdk/1.2

\section{AUTHORS PROFILE}

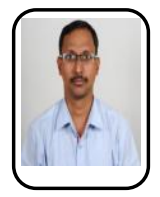

Dr.S.Joshua Kumaresan is working as Associate professor in the department of ECE of R.M.K. Engineering college. He completed his Ph.D in the area of image processing in 2018 , M.E (VLSI Design) in 2007 both from Anna university Chennai. He also completed M.S (Electronics and Control) from BITS, Pilani in 1999 and B.E (ECE) in 1994 from Bharathidasan University. He has 23 years of teaching experience which includes both UG and PG. and 1 year he worked in an industry as R\& D engineer. He published more than 20 papers in international journal and conferences. He published books on Electromagnetic Fields, Digital Electronics, Digital Principles system design and Digital logic circuits. . He guided many projects at UG \& PG levels. He also mentored and guided many students for various competitions like Smart India Hackathon, Arm design contest, India Innovation challenge design contest 2018 etc. He organized many college level National conferences and symposiums. He is a member of professional societies IEI, ISTE, ISRO-ISSE, and IACSIT.

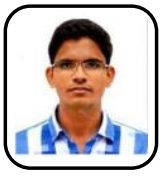

R.Nethaji Subash Chandra is working as dot net develope in $\mathrm{HnS}$ infotech, Chennai. He completed his B.E from R.M.K Engineering college in 2019. He is a member of ISTE. He developed sales order Management for Hyundai. His area of interest includes ASP.net, SQL etc.

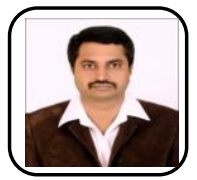

Dr. T. Manikandan is a Professor working at Rajalakshmi Engineering College, Thandalam, Chennai. He has completed his Ph.D titled "A study on computer-aided diagnosis systems for lung cancer detection and its three dimensional visualization using machine learning techniques" at Anna University, Chennai during January, 2017. He did his bachelor's degree in Engineering from Vellore Engineering College, Chennai under Madras University \& master's degree in Engineering from College of
Engineering, Anna University, Guindy, Chennai during 1998 \& 2007 , respectively. He is having 21 years of teaching experience which includes both UG and PG. He also guided many projects at UG \& PG levels. He has 50 papers in refereed international journals and conferences in his credit. He is serving as editorial board member for various international journals such as International journal of Biomedical and Healthcare Sciences, Archives of General Internal Medicine, Journal of Cancer Diagnosis, Journal of Medical and Clinical Oncology, Journal of Clinical Epigenetics and Integrative Cancer Biology and Research.

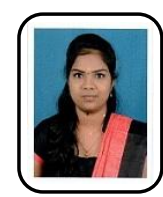

R.Priyanka pursued her B.E Degree in Electronics and Communication Engineering in 2015 and M.E degree in Applied Electronics from R.M.K Engineering College in 2017. She is pursuing her Ph.D degree and working as an Assistant Professor in ECE Department at Saveetha school of Engineering. She has a teaching experience of 2 years. Her Intelligence. area of research includes Machine learning and Artificial

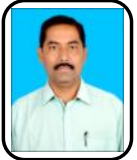

Dr. A. Muruganandham received the B.E. Degree in Electronics and Communication Engineering and M.E., degree in Communication systems from University of Madras and National Institute of Technology (NIT), Trichy in 1993 and 2000, respectively. He completed the $\mathrm{Ph} . \mathrm{D}$ (Image Compression) degree in Anna University in the year 2013, Chennai. He is a life member of ISTE, FIE and member of IEEE. He is currently working as a Professor in the Department of Electronics and Communication Engineering, at Rajarajeswari College of Engineering, Bengaluru, Karnataka, India and has a teaching experience of 23 years. His-research interests includes Image processing and Bio Medical Engineering. 